\title{
Precursor-derived Si-B-C-N ceramics
}

\author{
Fritz Aldinger, Markus Weinmann and Joachim Bill \\ Pulvermetallurgisches Laboratorium ( $P M L)$, \\ Max-Planck-Institut fir Metallforschung and \\ Institut für Nichtmetallische Anorganische Materialien \\ Universität Stuttgart, Heisenbergstraße 5, D-70569 Stuttgart, Germany
}

\begin{abstract}
In recent years, the pyrolysis of preceramic organometallic compounds became of increased interest for the synthesis of new inorganic materials. The main objective of this process route is to build up novel materials from molecular units in order to design the material on an atomic scale. According to this process, preceramic polymers are synthesized from monomer units. After cross-linking of such precursors, the obtained preceramic networks will be transformed by pyrolysis into amorphous materials. Further increase of the temperature yields thermodynamically metastable and/or stable crystalline phases.
\end{abstract}

Because of the fraction of covalent bonding providing high thermally, chemically and mechanically stable materials, materials based on the Si-B-C-N system are of special interest. Bulk materials, coatings, and fibers of such materials reveal quite interesting high temperature properties.

\section{INTRODUCTION}

In the process of the pyrolysis of preceramic compounds (Fig. 1) proper monomer units are polymerized and cross-linked into organometallic preceramic networks.

The networks are then subsequently pyrolized at elevated temperatures providing inorganic materials of great scientifical and technical interest. Since the first proposal of this concept by Chentrell and Popper (1) several research groups in Germany, USA, Japan and France have been working in this field. The achievements of these groups and the ongoing activities in the exploration of chemical synthesis routes for the production of proper preceramic networks, the controlled decomposition of the preceramics into inorganic materials as well as the characterization and technical aspects of many different materials have been reviewed in several articles (2-8). The idea behind the process of the pyrolysis of preceramic compounds is to build up organometallic polymeric chains of structural units of the ceramic materials. The goal is to synthesize the macromolecules at first and then to condense them at relatively low temperatures into inorganic materials.

Several aspects make this technique most attractive for the development of new materials and components:

1. With this technique one can produce amorphous materials eventually well away of those known from thermodynamic stable and most strongly stoichiometric compounds, with compositions not obtainable with common materials synthesis.

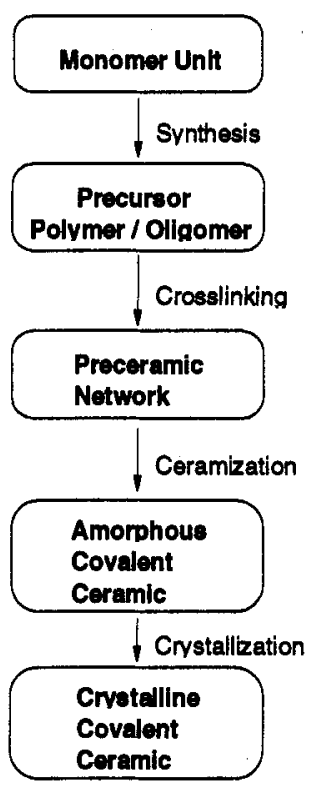

Fig. 1 Material design by molecular architecture. 
2. Because of the low mobility in predominantly covalent bonded materials the amorphous stage can be thermally stable to very high temperature before transforming into crystalline phases.

3. One can control the thermal activation in the amorphous stage for material transport mechanisms. This gradually provides the means for the kinetic stabilization of less stable phases and microstructures with morphologies not possible by common material synthesis routes (e.g. melting or sintering). In these highly thermally activated processes, such sensitive features are lost when the activated system "falls down" to a low level of energy.

4. Taking advantage of the various fabrication capabilities of polymer process engineering, components such as fibers, coatings, infiltration and complex-shaped bulk parts can mostly be produced in an easy manner.

It is the purpose of this paper to outline the general methods of the synthesis of ceramic materials via thermolysis of preceramic compounds. This outline will consist of general information taken from the literature with special consideration of our own results created by former collaborators at Hoechst AG and by the present research group at the PML.

\section{PRECURSOR SYNTHESIS}

Since the type of the backbone and the functional side chains of precursor molecules substantially influence the ceramic yield, chemical composition, and microstructure of precursor-derived ceramics a variety of different compounds has been investigated as starting materials. Figure 2 shows examples of the polymers which have been synthesized from monomers for the preparation of silicon carbide and silicon nitride-based ceramics as reviewed (2-8).

These polymers are characterized by a direct attachment of silicon to carbon and/or nitrogen. Boron-containing polycarbosilazanes (9-12), carbon containing polyborosilazanes (13-15) and silylated borazine derivatives (16-20) have been shown to be excellent precursor molecules to ceramic materials in the quaternary system Si-B$\mathrm{C}-\mathrm{N}$. In general, these molecules consist of Si-N skeletons, which are more or less cross-linked via B, B-N, B-C or borazine units, carrying different substituents bonded to the silicon centers.

Recently, substantial progress has been made by the synthesis of boron-modified polysilazanes and polysilylcarbodi-imides $(10,21-25)$ using vinyl groups for the attachment of boron. In order to

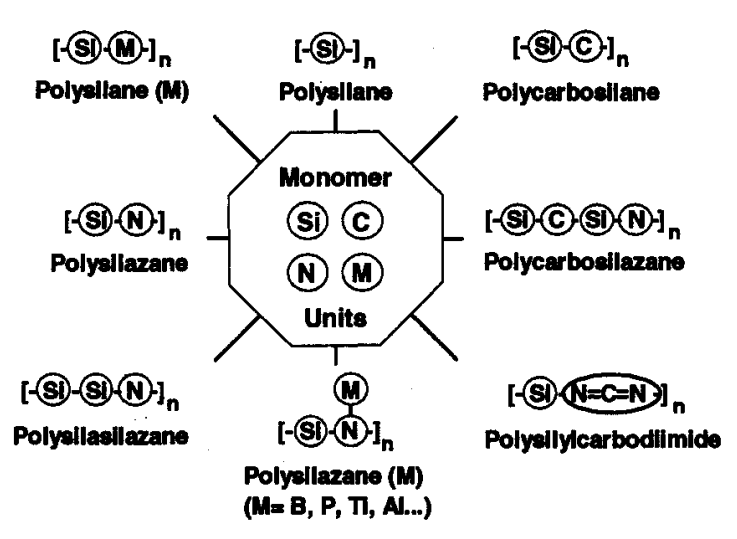

Fig. 2 Formation of non-oxide organic silicon polymers from monomer units. understand the cross-linkage capabilities of the polymers, the reduction of mass loss during thermolysis and salt-free polymerization have been investigated for different reaction pathways. They are based on the either so-called "monomer route (M)" or the "polymer route (P)". The monomer route is characterized by the transformation of functionalized monomer units into a preceramic polymer (e.g. ammonolysis of Tris(methyldichlorosilyl-ethyl)borane 2) yielding the boron modified polysilazane $3 \mathbf{M}$ :

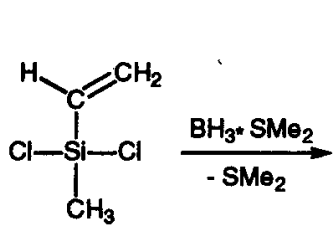

1

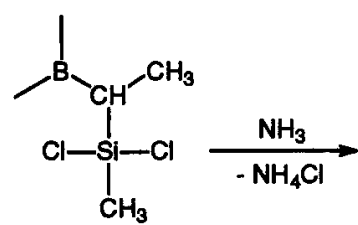

2

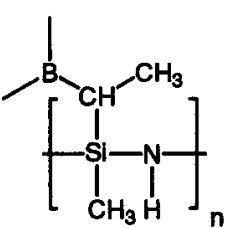

$3 \mathbf{M}$ 
The polymer route is achieved by the functionalization of a polymeric precursor $(e . g$. hydroboration of polymethylvinylsilazane 4):<smiles>C=C(Cl)C(C)(N)Cl</smiles><smiles>C=C1CCC(C)N1[Si]1(C)CCCC1</smiles>

4

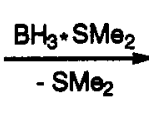<smiles>CC1CCCN1[Si](C)(C)C(C)C</smiles>

$3 \boldsymbol{P}$

Using a co-ammonolysis of chlorosilanes and hydroborated dichloromethylvinylsilane the boron content can be varied within certain limits. An increase of cross-linkage was performed by the substitution of the Si-bonded methylgroups towards more reactive groupings using trichlorovinylsilane as the monomeric starting compound:<smiles>C=C(C)[Si](Cl)(Cl)Cl</smiles>

5<smiles>CB(C)C(C)[Si](N)(Cl)Cl</smiles>

6<smiles>CN[Si]1(NC)NC(C)CCC(C)C1C</smiles>

$7 \boldsymbol{M}$

The reaction results in a highly cross-linked preceramic network and an increased ceramic yield. However, the separation of the polymer and $\mathrm{NH}_{4} \mathrm{Cl}$ is difficult.

The substitution of the Si-bonded methyl groups towards lower weight groupings as hydrogen essentially increases the ceramic yield. This reduces the shrinkage during thermolysis, which is of great importance with respect to technical application (26):

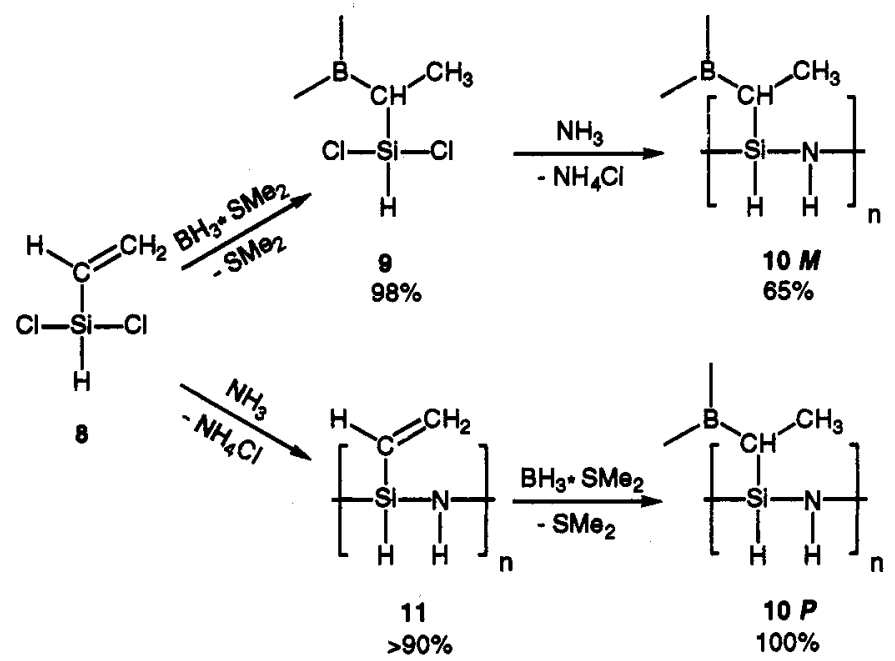

The polymer route offers a very high output. The reaction is inexpensive and rapid and creates no waste. A point of even greater importance is that the ceramic yields of both 10M and 10P are very high (Fig. 3) as compared to the methyl substituted derivatives. In addition, the thermal stability of the derived ceramic is remarkable (Fig. 4). 


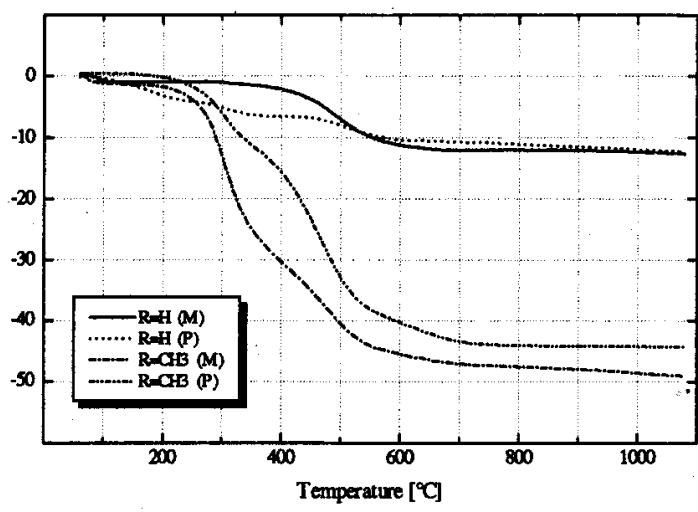

Fig. 3 Thermogravimetric analysis of boron modified polysilazanes of type $\left\{\mathrm{B}\left[\mathrm{C}_{2} \mathrm{H}_{4} \mathrm{Si}(\mathrm{R}) \mathrm{NH}\right]_{3}\right\}_{n}$ (heating rate: $2 \mathrm{~K} / \mathrm{min}$, argon; $M=$ monomer route, $P=$ polymer route).

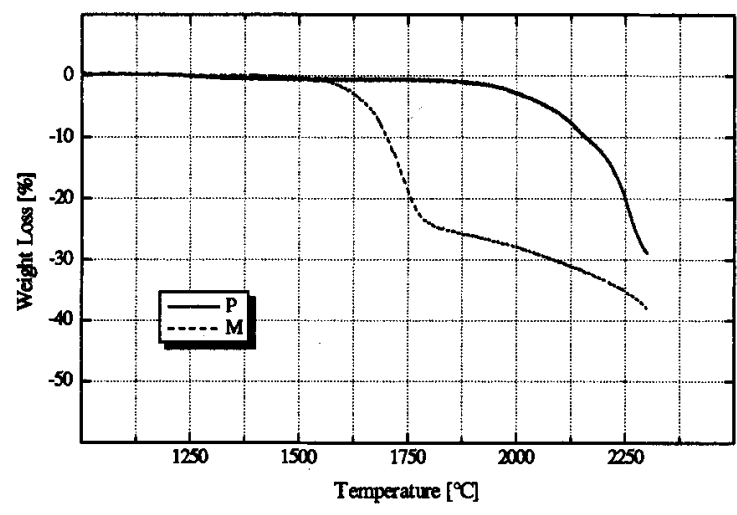

Fig. 4 High temperature thermogravimetric analysis of amorphous $\mathrm{Si}-\mathrm{B}-\mathrm{C}-\mathrm{N}$ ceramics obtained from boron modified polysilazanes of type $\left\{\mathrm{B}\left[\mathrm{C}_{2} \mathrm{H}_{4} \mathrm{Si}(\mathrm{H}) \mathrm{NH}\right]_{3}\right\}_{n}$ (heating rate: $2 \mathrm{~K} / \mathrm{min}$, argon; $\mathrm{M}=$ monomer route, $\mathrm{P}=$ polymer route)

For commercialization of the thermolysis of preceramic compounds a salt-free polymerization reaction is of great interest. In general, this can be achieved by using the reaction of chlorosilanes with bis(trimethylsilyl)carbodi-imide to synthesize polysilylcarbodi-imides as precursors for Si-C-N ceramic composites $(10,24,27)$ :

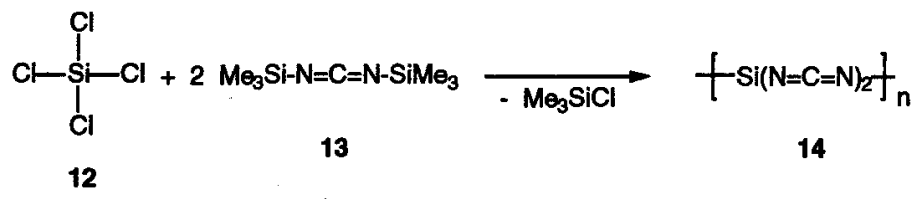

Since hydroboration of polysilylcarbodi-imides does not result in defined Si-B-C-N precursors, several alternative routes have been investigated $(21,28)$. The most promising is the synthesis of boron modified polysilylcarbodi-imides via the reaction of bis(trimethylsilyl)carbodi-imide with hydroborated vinylchlorosilanes:

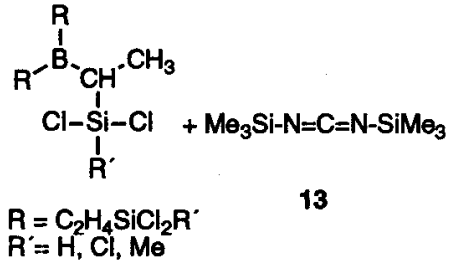

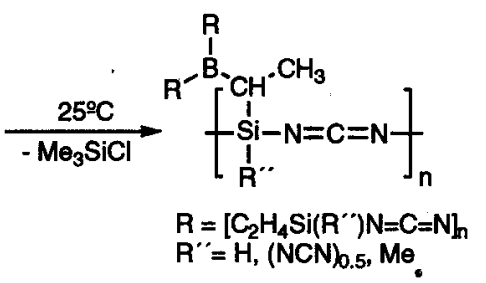

15

$\mathrm{R}^{\prime}$ could either be $\mathrm{H}, \mathrm{Cl}$ or methyl and $\mathrm{R}^{\prime \prime}$ is therefore $\mathrm{H},(\mathrm{NCN})_{0.5}$ or methyl. These reactions are not only inexpensive and rapid and have a yield of $100 \%$ but create no salts or waste, because methyltrichlorosilane, the only reaction product beside the borated polysilylcarbodi-imides 15 can be recycled easily $(21,28)$.

Using excess 13, these reactions show sol-gel characteristics:

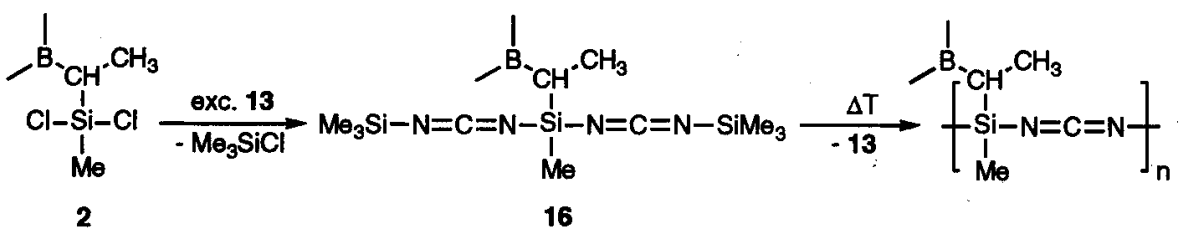


Excess bis(trimethylsilyl)carbodi-imide can be recycled. This reaction is the first non-oxide sol-gel process for the synthesis of Si-B-C-N ceramic precursors and offers a substantial potential for the production of precursor derived ceramics (28).

\section{THERMOLYSIS}

The reactions which occur during thermolysis are still not cleared up in detail. Figure 5 describes schematically the formation of ternary $\mathrm{Si}_{3} \mathrm{~N}_{4} / \mathrm{SiC}$ composites from cyclic oligosilazane. NMR studies (29) have shown that at temperatures below $500^{\circ} \mathrm{C}$ cross-linking by reactions like dehydrogenation between $\mathrm{N}-\mathrm{H}$ and $\mathrm{Si}-\mathrm{H}$ groups occurs. Between $500^{\circ} \mathrm{C}$ to $700^{\circ} \mathrm{C}$, ceramization takes place and methyl groups split off yielding an amorphous silicon carbonitride. At temperatures higher than $900^{\circ} \mathrm{C}$ residual hydrogen is removed. ${ }^{29} \mathrm{Si}$ and ${ }^{13} \mathrm{C}$ solid state NMR studies were performed on a series of ternary silazanes after thermolysis of a commercial polyhydridomethylsilazane (PHMS, NCP200 of Chiosso Crop., Tokyo, Japan). The results at different temperatures revealed a short range order of the elements consisting mainly of tetrahedral $\mathrm{SiC}_{\mathrm{x}} \mathrm{N}_{\mathrm{y}}(\mathrm{x}+\mathrm{y}=4)$ units and $\mathrm{sp}^{3}$-hybridized carbon. However, the short range order of silicon carbonitrides is directly correlated with the molecular structure of the polymer. This has been demonstrated in the case of the thermolysis of a commercially available polyvinylsilazane (PVS, VT50, Hoechst AG, Germany) which results in $\mathrm{SiN}_{4}$ tetrahedral units and $\mathrm{sp}^{2}$-hybridized carbon. Against this, the effect of boron on the reactions during thermolysis is not clearly understood.
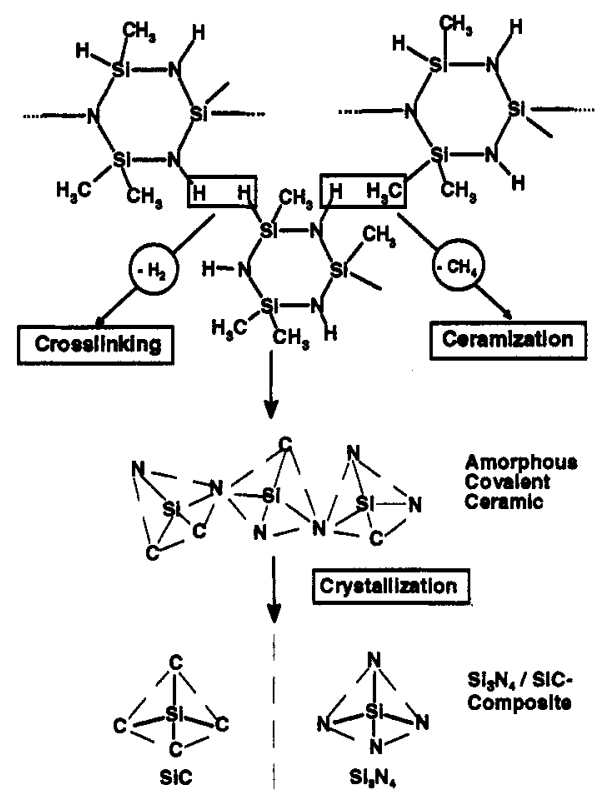

Fig. 5 Schematical description of the formation of $\mathrm{Si}_{3} \mathrm{~N}_{4} / \mathrm{SiC}$ composites from cyclic oligosilazane.

\section{THERMOCHEMISTRY}

For the development of Si-B-C-N materials the constitution of this system has been established (30). Using the CALPHAD method a consistent set of data has been calculated for this system. For the $\mathrm{B}_{4} \mathrm{C}$ phase, which crystallizes in the $R \overline{3} \mathrm{~m}$ spacegroup a thermodynamic model has been developed which allows the analytical description of the extended solubility range of this phase and the thermodynamic optimization of the B-C system. The other binaries have been re-optimized on the basis of the latest thermodynamic data known from literature. Since there are no extended stable ternary or higher component phases or ternary solid solutions known, a reliable extrapolation into ternary and quaternary compositions can be made. The only correction was to allow a restricted solid solubility of boron in $\mathrm{SiC}$ within the $\mathrm{Si}-\mathrm{B}-\mathrm{C}$ system.

Figure 6 and Fig. 7 show the invariant five-phase equilibrium $\mathrm{L}+\mathrm{Si}+\mathrm{SiC}+\mathrm{B}_{4} \mathrm{C}+\mathrm{BN}$ at $\mathrm{T}=1687 \mathrm{~K}$ calculated from the data set and an isothermal section at $\mathrm{T}=1673 \mathrm{~K}$ with the four-phase equilibria important for materials development (31), respectively.

Very valuable in this respect are phase fraction diagrams. These diagrams can be computed from the data set for each material composition of interest. Figure 8 shows the phase fraction diagram for the composition of 42.4 at.- $\% \mathrm{Si}, 5.8$ at. $-\% \mathrm{~B}, 25.5$ at. $-\% \mathrm{C}$ and 26.3 at. $\% \mathrm{~N}$. This composition is of interest for the development of silicon carbide - silicon nitride nano-nano composites as will be shown below. The thermodynamic modeling of the metastable amorphous state in order to describe in detail its transformation into the stable phases will be difficult. 


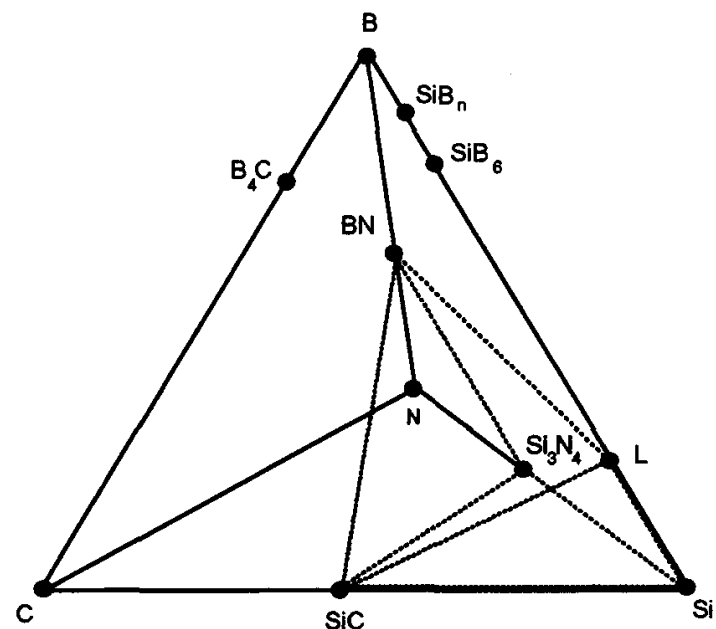

\begin{tabular}{|c|c|c|}
\hline $2583 \mathrm{~K}$ & $\mathbf{G}+\mathbf{L}$ & $=\mathrm{BN}+\mathrm{SiC}+\mathrm{C}$ \\
\hline $2558 \mathrm{~K}$ & $\mathbf{L}+\mathbf{C}$ & $=\mathrm{BN}+\mathrm{SiC}+\mathrm{B}_{4} \mathrm{C}$ \\
\hline $311 \mathrm{~K}$ & $\mathbf{L}+\mathbf{B}$ & $=\mathrm{B}_{4} \mathrm{C}+\mathrm{B}_{n} \mathrm{Si}+\mathrm{BN}$ \\
\hline $2123 \mathrm{~K}$ & $\mathbf{L}+\mathbf{B}_{\mathbf{n}} \mathbf{S i}$ & $=B_{6} S i+B_{4} C+B N$ \\
\hline $113 \mathrm{~K}$ & $\mathbf{G}+\mathbf{L}$ & $=\mathrm{Si}_{3} \mathrm{~N}_{4}+\mathrm{SiC}+\mathrm{BN}$ \\
\hline $1762 \mathrm{~K}$ & $\mathbf{G}+\mathbf{S i C}$ & $=\mathbf{C}+\mathrm{Si}_{3} \mathbf{N}_{4}+\mathrm{BN}$ \\
\hline $1687 \mathrm{~K}$ & $\mathbf{L}$ & $=S i+S i C+B_{4} C+B N$ \\
\hline $1686 \mathrm{~K}$ & $\mathbf{L}+\mathbf{S i}_{3} \mathbf{N}_{4}$ & $=\mathbf{S i}+\mathbf{B N}+\mathbf{S i C}$ \\
\hline $1669 \mathrm{~K}$ & $\mathbf{L}+\mathbf{S i C}$ & $=\mathbf{B}_{4} \mathbf{C}+\mathbf{S i}+\mathbf{B N}$ \\
\hline $1657 \mathrm{~K}$ & $L+B_{4} C$ & $=\mathbf{S i}+\mathrm{B}_{6} \mathbf{S i}+\mathbf{B N}$ \\
\hline $471 K$ & $\mathrm{~B}_{6} \mathrm{Si}+\mathbf{S i}$ & $=B_{3} S i+S i+B_{4} C$ \\
\hline
\end{tabular}

Fig. 6 Invariant five-phase equilibrium $\mathrm{L}+\mathrm{Si}+\mathrm{SiC}+\mathrm{B}_{4} \mathrm{C}+\mathrm{BN}$ at $T=1686 \mathrm{~K}$ (top) and possible five-phase equilibria at different temperatures (below).

\section{MICROSTRUCTURE DEVELOPMENT}

As already mentioned, with thermolysis the preceramic polymer network will be transformed into an amorphous stage. Nothing is known about the structure of quaternary amorphous. However, from wide and small angle X-ray and neutron diffraction measurements (32) as well as from solid state NMR it is known that there is a short range ordering with carbon and/or nitrogen tetrahedrally coordinated to silicon $(29,33)$. With respect to boron it has been argued that it reveals a planar coordination (33). In a material placed to the tie line between carbon and silicon nitride into amorphous carbon and amorphous $\mathrm{Si}_{3} \mathrm{~N}_{4}, \mathrm{X}$-ray and neutron diffraction studies also reveal that ternary Si-C$\mathrm{N}$ materials are segregated into two amorphous phases (32). There are indications that the amorphous segregates agree in composition with that of the crystalline equilibrium phases. However, this suggestion needs further investigations before it can be generalized.

Obviously the kinetics of the crystallization of the amorphous state is significantly influenced by the composition. Boron e.g. substantially retards the crystallization of amorphous Si-C-N materials (15,34-36). Depending on the boron content the amorphous stage is metastable up to $1800^{\circ} \mathrm{C}$ before it crystallizes into the stable phases $(8,34,36)$. It is interesting to note that with certain composition upon crystallization nano-
Fig. 7 Four-phase equilibria in the Si-B-C-N system at $1673 \mathrm{~K}$.

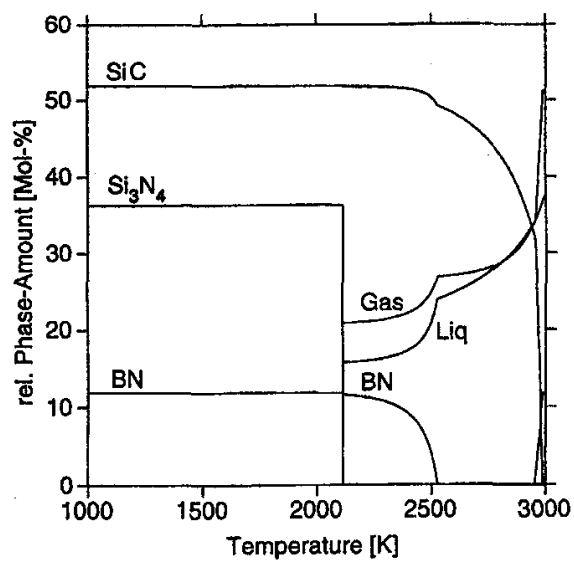

Fig. 8 Si-B-C-N phase fraction diagram for composition $42.2 \mathrm{Si}, 5.8 \mathrm{~B}, 25.5 \mathrm{C}, 26.3 \mathrm{~N}$ (at.-\%). 
sized silicon carbide and nano-sized silicon nitride grains are formed which do not show noticeable grain growth even at temperatures as high as $1750^{\circ} \mathrm{C}$. Boron-free ternary materials with similar composition in silicon, carbon and nitrogen crystallize at substantial lower temperatures (approx. $1350^{\circ} \mathrm{C}$ ) by forming nano-sized silicon carbide embedded in micro-sized silicon nitride grains (Fig. 9). The reason for this behavior appears to be the low mobility of boron during the formation of silicon carbide and silicon nitride giving rise to the formation of turbostratic grain boundary phase consisting of boron, carbon and nitrogen (Fig. 10).

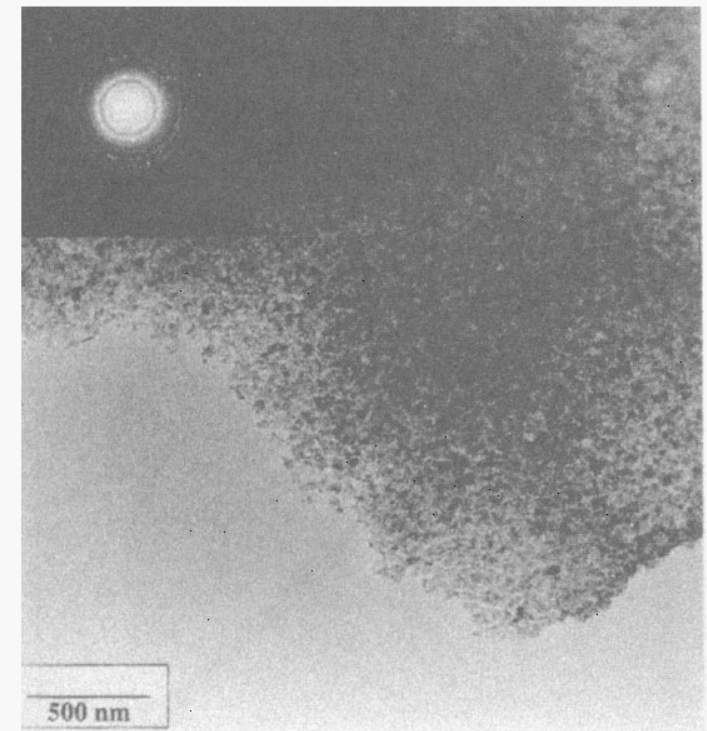

Fig. 9 HR TEM image of nano-sized silicon carbide embedded in micro-sized silicon nitride grains

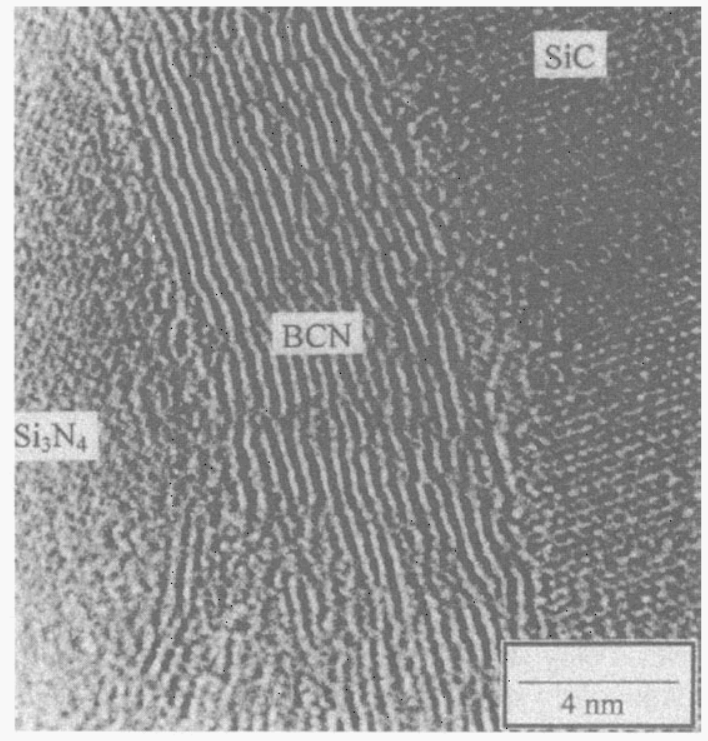

Fig. $10 \mathrm{HR}$ TEM image of a $\mathrm{SiC}$ and a $\mathrm{Si}_{3} \mathrm{~N}_{4}$ grain with a turbostratic grain boundary B-C-N segregation.

\section{PRECURSOR PYROLYSIS ENGINEERING}

The production of precursor-derived ceramics takes advantage of highly developed polymer process engineering. Powders, fibers, coatings, bulk materials, infiltration and other types of preforms can be produced by techniques well known from polymer process engineering followed by a pyrolysis step (Fig. 11).

Of special interest is the production of dense bulk material. This is not trivial, since the condensation reactions during pyrolysis are combined with the evolution of gases like $\mathrm{H}_{2}$, $\mathrm{NH}_{3}$ and $\mathrm{CH}_{4}$. These species degas easily with the manufacture of fibers or coatings,

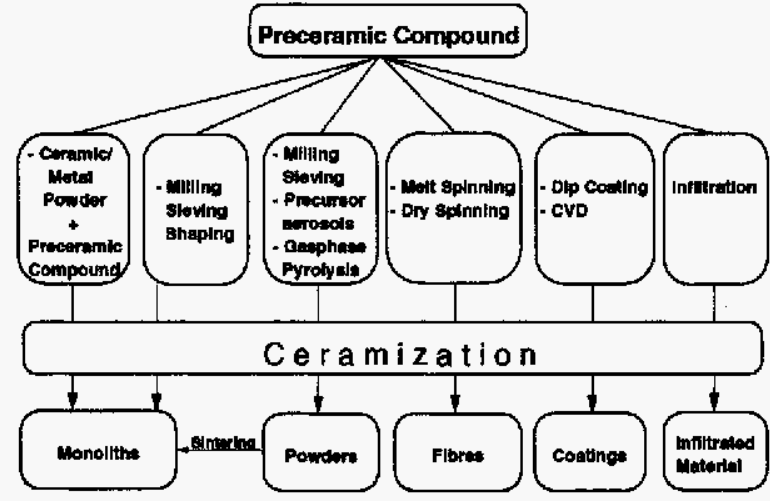

Fig. 11 Preparation of ceramic materials by precursor processing. i.e. with shapes which are thin in at least one dimension. In bulk material, however, such gases leave pores behind, which do not close during pyrolysis due to the high viscosity of the resulting material. In order to reduce porosity the compaction of the polymer powder was done at elevated temperature $(28,37)$. Using this technique the porosity of as-pyrolyzed Si-B-C-N material could be reduced to less then $5 \%$, depending on the temperature and the pressure applied (Fig. 12, 13). 


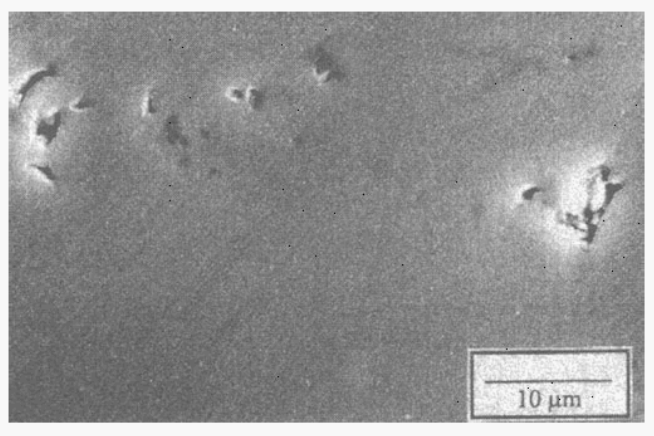

Fig. 12 SEM micrograph of a polished surface of an amorphous Si-C-N ceramic obtained by thermolysis of warm pressed polyvinylsilazane powder.

Since such types of precursor-derived materials do not contain grain boundaries, mechanical properties at high temperatures should be better than of those obtained by conventional methods (e.g. liquid phase sintering). Preliminary creep studies at $1400^{\circ} \mathrm{C}$ to $1550^{\circ} \mathrm{C}$ and at stresses between $100 \mathrm{MPa}$ and $300 \mathrm{MPa}$ for up to $300 \mathrm{~h}$ reveal only a primary stage creep i.e. continuously decreasing creep rates. There is almost no difference with temperature (Fig. 14) and the stress exponent is below one.

Coatings have been produced by dip coating substrates into precursor solutes and subsequent conversion into inorganics by pyrolysis (38).

Thermogravimetric investigations of coatings based on amorphous $\mathrm{SiC}_{1.5} \mathrm{~N}_{0.7} \mathrm{~B}_{0.3}$ at 1400 ${ }^{\circ} \mathrm{C}$ in air confirm that the oxidation of a $\mathrm{C} / \mathrm{C}$ $\mathrm{SiC}$ substrate was almost totally prevented (Fig. 15). The reasons for the oxidation proof of this coating, which offers selfhealing capabilities, are not yet clearly understood. However, it is obvious that the amorphous state with its very low diffusivity due to the covalent character of the material in combination with the formation of silicabased passivating surface layers play an important role.

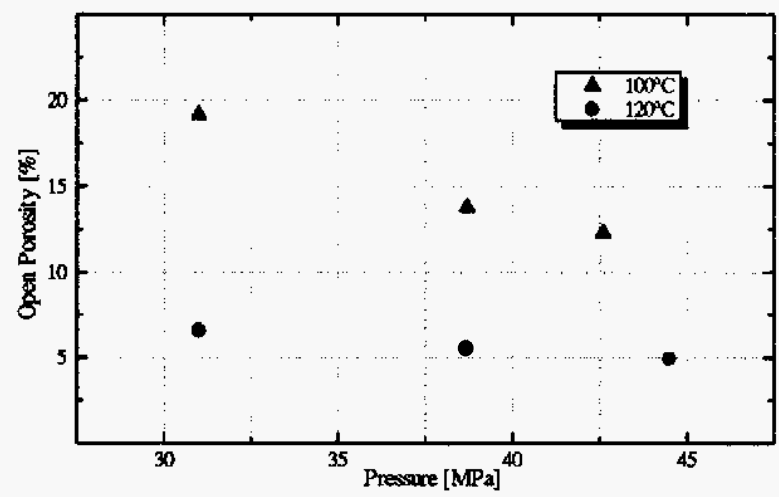

Fig. 13 Correlation of pressure applied for Plastic Forming and total sample porosity of ceramic monoliths obtained from $\left[\mathrm{B}\left[\mathrm{C}_{2} \mathrm{H}_{4} \mathrm{Si}(\mathrm{H}) \mathrm{NCN}\right]_{3}\right\}_{n}$ (15).

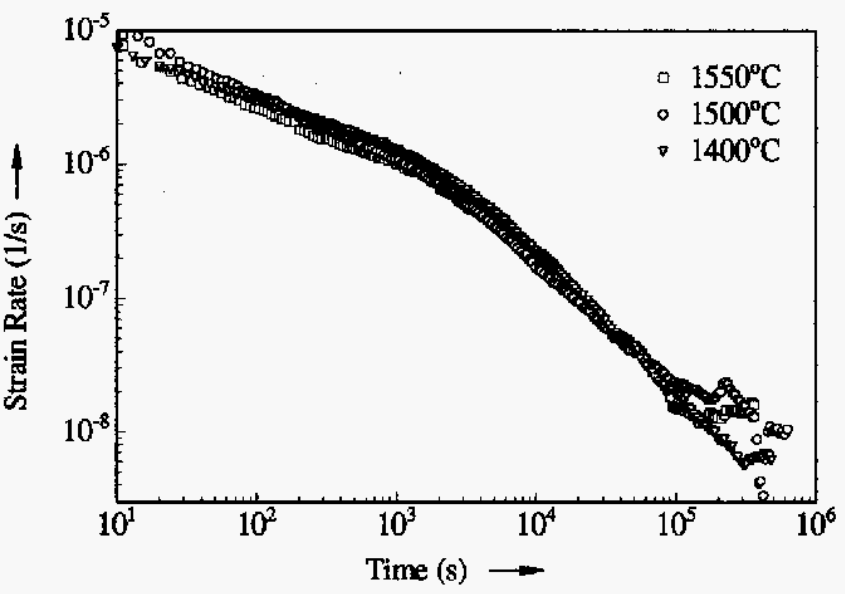

Fig. 14 Creep behavior of polyvinylsilazane-derived silicon carbonitride at $100 \mathrm{MPa}$.

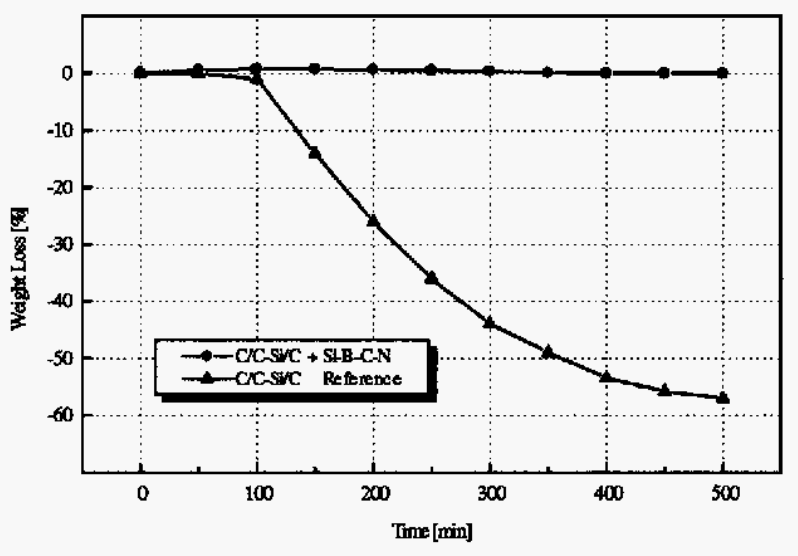

Fig. 15 Oxidation behavior (TGA) of uncoated C/C-Si/C substrate and Si-B-C-N coated C/C-Si/C substrate at $1400^{\circ} \mathrm{C}$ (Coating solution: $25 \%$ in toluene +42 vol. $\%$ Si; thermolysis: $1000^{\circ} \mathrm{C}, \mathrm{N}_{2}$ ). 
The production of Si-B-C-N ceramic fibers (Fig. 16) was realized by thermolysis (heating rate: $1.7 \mathrm{Kmin}^{-1}, 298-1373 \mathrm{~K}$ ) of polymeric "green fibers" which themselves were produced from concentrated thf solutions of hydroborated polymethylvinylsilazane by dry spinning processes. It has been shown that the diameter of the fibers obtained, directly depended on the concentration of the polymer solution and the rate of extension whereby increasing the latter was directly reflected in increased fiber diameters. The density of the as-obtained ceramic Si-B-C-N fibers was determined to be $2.5 \mathrm{~g} / \mathrm{cm}^{3}$. The tension strength and the Young modulus were $0.59 \mathrm{GPa}$ and $68 \mathrm{GPa}$.

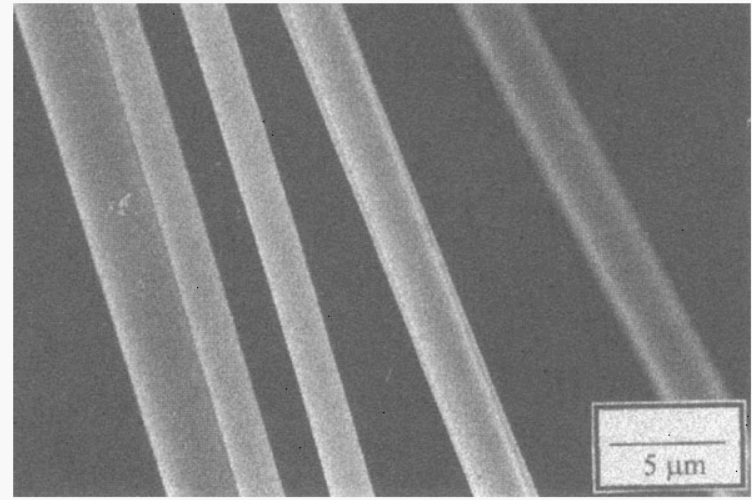

Figure 16: SEM photograph of Si-B-C-N amorphous ceramic fibers prepared by thermolysis of green fibers of $\left\{\mathrm{B}\left[\mathrm{C}_{2} \mathrm{H}_{4} \mathrm{Si}\left(\mathrm{CH}_{3}\right) \mathrm{NH}\right]_{3}\right\}_{n}(\mathbf{3 M})$.

\section{CONCLUSIONS}

It has been shown that the preparation of Si-B-C-N ceramic composites from element organic polymers is a suitable method for the synthesis of high temperature stable materials. The polymer syntheses are realized on different reaction pathways (e.g. dehydrogenation from hydridosilazanes and borazine derivatives or by ammonolysis of suitable boron containing chlorosilanes or chlorosilylaminodichloroborane). A new class of $\mathrm{Si}-\mathrm{B}-\mathrm{C}-\mathrm{N}$ precursors are boron containing polysilylcarbodi-imides which can be obtained from a non oxide sol-gel process of bis(trimethylsilyl)carbodi-imide and hydroborated vinylchlorosilanes. The advantage of this non oxide-sol gel process as compared to common methods (e.g. ammonolysis of chlorosilanes) is the significantly facilitated work-up. It has been shown that polymer solutions of boron containing polysilazanes of convenient viscosity are applicable for both, the production of oxygen resistant fibers and coatings. Moreover it has been determined that boron modified polysilylcarbodi-imides are outstanding precursors for the production of dense bulk ceramics. The as-obtained preceramics are then transformed into amorphous ceramics by subsequent thermolysis. Depending on the structure of the amorphous state, which is still not known in detail, the metastable amorphous ceramics crystallize at higher temperatures into the thermodynamically more stable crystalline materials. HR TEM investigations point to the fact that the diffusion controlled crystallization may be significantly hindered by a turbostratic B-C-N grain boundary phase between nanosized $\mathrm{SiC}$ and $\mathrm{Si}_{3} \mathrm{~N}_{4}$ particles. This results in an unusual kinetic thermal stabilization of the amorphous state.

\section{ACKNOWLEDGMENTS}

The authors grateful acknowledge the supporting co-workers at the PML: Dr. H.-J Seifert (Thermochemistry), Dr. A. Jalowiecki (Microstructure development), Dr. S. Seitz (Plastic forming), R. Haug (Plastic forming, thermolysis), S. Katz (preparative chemistry, mercury pressure porosimetry), J. Dürr (X-Ray and neutron diffraction), J. Schuhmacher (solid state NMR) and H. Kummer (TGA Analysis). Dr. J. Bill is acknowledged for helpful discussions. For financial support we thank the Deutsche Forschungsgemeinschaft Bonn (DFG), the Fonds der Chemischen Industrie Frankfurt, the Japan Science and Technology Corporation (JST) and the Keramikverbund Karlsruhe-Stuttgart (KKS). 


\section{REFERENCES}

1. P. Popper, Brit. Ceram. Res. Assn. special Publ. 57, 1 (1967).

2. See several articles in R. M. Laine (Editor), Transformation of Organometallics into Common and Exotic Materials: Design and Activation, Proceedings of the NATO Advanced Research Workshop, Cap D'Agde (France, 1986).

3. K. Wynne, M. Zeldin and H. Allcock (Editors), Inorganic and Organometallic Polymers, Am. Chem. Soc. Symp. Ser. 360 (1988).

4. R. T. Paine and C. K. Narula, Chem. Rev. 90, 73(1990).

5. J. Bill and F. Aldinger, Adv. Mater. 7, 775 (1995).

6. M. Birot, J.-P. Pillot and J. Dunoguès, Chem. Rev. 95, 1443 (1995).

7. W. Toreki, Polymer News 16, 6 (1991).

8. H.-P. Baldus and M. Jansen, Angew. Chem. Int. Ed. Engl. 36, 328 (1997).

9. M. Takamizawa, T. Kobayashi, A. Hayashida and Y. Takeda, US Pat. 4,604,367 (1986).

10. A. Kienzle, Thesis, Universităt Stuttgart (1994).

11. J. Bill, A. Kienzle, M. Sasaki, R, Riedel and F. Aldinger, in Ceramics: Charting the Future, P. Vincenzini, Editor p 1291 (1995).

12. R. Riedel, A. Kienzle, W. Dressler, L. Ruwisch, J. Bill and F. Aldinger, Nature 382, 796 (1996).

13. M. Jansen and H.-P. Baldus, Ger. Offen. DE 4107108 A1, (1992).

14. H.-P. Baldus, O. Wagner and M. Jansen, Mat. Res. Soc. Symp. Proc. 271, 821 (1992).

15. H.-P. Baldus, M. Jansen and O. Wagner, Key Engineering Materials 89-91, 75 (1994).

16. D. Seyferth and H. Plenio, J. Amer. Ceram. Soc. 73, 2131 (1990).

17. D. Seyferth, H. Plenio, W. S. Rees Jr. and K. Büchner, Silicon Ceramics with a Dash of Boron in Frontiers of Organosilicon Chemistry, The Royal Society of Chemistry, Cambridge (1991).

18. K. Su, E. E. Remsen, G. A. Zank and L. G. Sneddon, Chem. Mater. 5, 547 (1993).

19. T. Wideman, K. Su, E. E. Remsen, G. A. Zank and L. G. Sneddon, Chem. Mater. 7, 2203 (1995).

20. T. Wideman, K. Su, E. E. Remsen, G. A. Zank and L.G. Sneddon, Mat. Res. Soc. Symp. Proc. 410, 185 (1996).

21. M. Weinmann, R. Haug, J. Bill, F. Aldinger, J. Schuhmacher and K. Müller, J. Organomet. Chem. in press.

22. M. Weinmann, Ultra-high Temperature Stable Ceramics from Inorganic Polymers, Proc. Workshop on Grain Boundary Dynamics of Precursor-Derived Covalent Ceramics, Schloß Ringberg, Germany, to be published (1997).

23. J. Pump and E. Rochow, Z. Anorg. Allg. Chem. 330, 101 (1964).

24. A. Kienzle, A. Obermeyer, R. Riedel, F. Aldinger and A. Simon, Chem. Ber. 126, 2569 (1993).

25. R. Riedel, A. Greiner, G. Miehe, W. Dreßler, H. Fueß, J. Bill and F. Aldinger, Angew. Chem. Int. Ed. Engl. 36, (1997).

26. M. Weinmann, J.Bill and F. Aldinger, Submitted to Adv. Mater.

27. A. Obermeyer, A. Kienzle, J. Weidlein, R. Riedel, and A. Simon, Z. Anorg. Allg. Chem. 620, 1357 (1994).

28. M. Weinmann, R. Haug, J. Bill, M. De Guire and F. Aldinger, submitted to Appl. Organomet. Chem.

29. J. Seitz, J. Bill, N. Egger and F. Aldinger, J. Eur. Ceram. Soc. 16, 885 (1996).

30. B. Kasper, Thesis, Universităt Stuttgart (1996).

31. H.-J. Seifert and F. Aldinger, Thermodynamic Calculations in the B-C-N-Si System, Proc. Workshop on Grain Boundary Dynamics of Precursor-Derived Covalent Ceramics, Schloß Ringberg, Germany, to be published (1997).

32. J. Dür, S. Schempp, P. Lamparter, J. Bill, S. Steeb and F. Aldinger, Solid State Ionics, in press.

33. M. Weinmann, J. Schuhmacher, K. Müller, J. Bill and F. Aldinger, unpublished results.

34. J. Bill, M. Fries, F. Aldinger and R. Riedel, Mat. Res. Soc. Symp. Proc. 271, 839 (1992).

35. J. Seitz and J. Bill, J. Mater. Sci. Lett. 15, 391 (1996).

36. A. Jalowiecki, J.Bill, F. Aldinger and J. Mayer, Composites 27A, 717 (1996).

37. J. Seitz, Thesis, Universität Stuttgart (1997).

38. D. Heimann, J. Bill and F. Aldinger, Fortschrittsberichte der Deutschen Keramischen Gesellschaft, WerkstoffeVerfahren-Anwendungen, Bd. 10, Keramische Schichten (1995). 